\title{
ASPECTOS BIOÉTICOS DEL CONSEJO GENÉTICO EN LA ERA DEL PROYECTO DEL GENOMA HUMANO
}

\author{
Manuel J. Santos Alcántara*
}

\begin{abstract}
Resumen: El conocimiento obtenido a la fecha acerca del Genoma Humano a través del Proyecto Genoma Humano (PGH), ha impactado profundamente en la medicina. La medicina en la era genómica se va tornando cada vez más preventiva que curativa. El conocimiento obtenido por el PGH ha permitido desarrollar tests de diagnóstico genético que pueden aplicarse a personas ya enfermas o a aquellas que todavía no han desarrollado una particular afección genética (diagnóstico presintomático). También estos tests pueden aplicarse para el diagnóstico antenatal y embrionario preimplantacional de enfermedades genéticas. En la aplicación de estos tests el Consejo Genético, en su calidad de acto médico, tiene un rol esencial. En este artículo se presentará el Proyecto del Genoma Humano, el proceso del Consejo Genético y sus implicancias bioéticas desde una perspectiva principialista y personalista.
\end{abstract}

Palabras clave: Proyecto Genoma Humano, bioética, consejo genético

\section{THE GENETIC COUNCIL'S BIOETHIC ASPECTS IN THE HUMAN GENOME PROJECT'S ERA}

\begin{abstract}
The Human Genome Project has had a significant impact in Medicine. Genomic Medicine is becoming more preventive than curative. The knowledge obtained by the Human Genome Project has allowed the development of genetic diagnostic tests for patients already affected (symptomatic diagnosis) or patients who will develop the condition in the future (presymptomatic diagnosis). These genetic tests may also be used in prenatal or preimplantational genetic diagnosis. Genetic counseling has a central role in the Genomic Medicine. This paper deals with the Human Genome Project and Genetic counseling from a bioethical point of view.
\end{abstract}

Key words: Human Genome Project, bioethics, genetic counseling

\section{ASPECTOS BIOÉTICOS DO CONSELHO GENÉTICO NA ERA DO PROJETO DO GENOMA HUMANO}

Resumo: O conhecimento obtido até hoje acerca do Genoma Humano através do Projeto Genoma Humano (PGH), impactou profundamente na Medicina. A Medicina na era genómica vai se tornando cada vez mais curativa. $\mathrm{O}$ conhecimento obtido através do PGH permitiu desenvolver testes de diagnóstico genético, que podem aplicar-se a pessoas já enfermas ou a aquelas que todavia não desenvolveram uma afecção genética particular (diagnóstico présintomático). Estes testes também podem ser aplicados para o diagnóstico pré-natal e embrionário de doenças genéticas. $\mathrm{Na}$ aplicação destes testes, o Conselho Genético, na sua qualidade de ato médico, tem um papel essencial. Neste artigo será apresentado o Projeto do Genoma Humano, o Processo do Conselho Genético e suas implicações bioéticas de uma perspectiva principialista e personalista.

Palavras-chave: Projeto Genoma Humano, bioética, conselho genético

* Departamento de Biología Celular y Molecular. Departamento de Pediatría. Facultad de Ciencias Biológicas. Facultad de Medicina. Pontificia Universidad Católica de Chile

Correspondencia: msantos@bio.puc.cl 


\section{Introducción}

A partir del año 1990 comenzó la revolución de la genética, con dos grandes acontecimientos que impactaron profundamente a la sociedad: se inició formalmente el Proyecto del Genoma Humano (PGH) y, por primera vez, seres humanos recibieron genes con el fin de modificar su patrimonio genético y curar ciertas enfermedades (terapia génica). Ello ha producido asombro y, a la vez, temor por parte de la sociedad, porque la ciencia en la actualidad cuenta con herramientas que nunca antes habían estado a su disposición, con las cuales puede cambiar el rumbo de la especie humana. Es un asunto que inquieta por la posibilidad de manipulación, y por sus eventuales implicancias sobre asuntos antes considerados propios de los designios de Dios y la naturaleza.

Con el desarrollo del PGH, la medicina ha entrado en una nueva era, la llamada "medicina genómica", que se caracteriza por un rol más preventivo que curativo. En esta era, los tests genéticos preventivos tienen un rol preponderante, ya que permiten realizar un screening de las mutaciones que posee una determinada persona, para informarle de los riesgos específicos de contraer patologías específicas en el futuro o, incluso, detectar enfermedades antes del nacimiento, desde el estado embrionario y fetal. En este escenario, que ya está teniendo lugar para variadas alteraciones genéticas conocidas, el Consejo Genético y sus implicancias bioéticas juegan un rol central.

\section{El Proyecto del Genoma Humano}

\section{Genes y ambiente}

Las características biológicas observables, normales o patológicas, de un ser humano (fenotipo), tales como el color de los ojos, la forma del pelo, la estatura, el coeficiente intelectual, la presión arterial, entre tantos otros, están determinadas por los genes -que se reciben de los padres- y el ambiente en el cual se desarrolla. El conjunto de genes de un individuo corresponde al genotipo. La totalidad de la información genética contenida en una célula humana es lo que se llama genoma humano.

Los seres humanos estamos formados por trillones de células (unidades básicas de todos los tejidos y órganos). Cada célula posee un citoplasma y un núcleo donde reside la información genética, distribuida en 46 cromosomas. El desarrollo de los seres humanos comienza en el momento de la fecundación cuando un espermatozoide (gameto masculino) fecunda a un óvulo (gameto femenino) originando una primera célula (cigoto), que, a su vez, originará todas las células de los organismos adultos. El espermatozoide aporta 23 cromosomas, el óvulo los otros 23 cromosomas, y después de la fecundación el cigoto los contiene todos (46).

Los cromosomas poseen muchos genes que corresponden a las unidades de herencia. La información genética se encuentra codificada en pequeños trozos de la molécula de ADN. El ADN (ácido desoxirribonucleico) es una molécula simple y de aspecto semejante a una escalera doblada en forma de hélice. Los "largeros" de la escalera están formados por moléculas de azúcar unidas a moléculas de fosfato y los "peldaños" por moléculas denominadas bases nitrogenadas (o "letras"). Existen cuatro bases nitrogenadas en el ADN: A (adenina); $\mathrm{G}$ (guanosina); $\mathrm{T}$ (timina) y $\mathrm{C}$ (citosina). Siempre A se une con $\mathrm{T}$ y $\mathrm{G}$ con $\mathrm{C}$, por tanto existen sólo dos tipos de peldaños: A-T y G-C. El ADN es una molécula extraordinariamente simple y, no obstante, toda la información genética reside en estas 4 letras que se disponen en una ordenación particular (o "secuencia") en un trozo de ADN. Las células humanas poseen alrededor de un metro y medio de ADN que está dividido en 46 trozos 
(los 46 cromosomas) en forma muy empaquetada.

Los genes corresponden a segmentos de esta molécula de $\mathrm{ADN}$, con una función particular $y$ caracterizados por una secuencia $u$ ordenación específica de estas 4 letras (bases nitrogenadas). En forma simple, molecularmente, un gen corresponde a una secuencia que determina una función específica, como por ejemplo, la formación de una proteína que cumpla un rol específico en las complejas vías metabólicas que presentan las diferentes células de nuestro organismo, o una proteína que forme alguna estructura celular.

\section{Objetivos del Proyecto del Genoma Humano}

Cada cromosoma está formado por una molécula de $\mathrm{ADN}$ y contiene cientos a miles de genes. En los 22 pares de cromosomas autosómicos humanos y en el par sexual $\mathrm{X}$ e $\mathrm{Y}$ existen aproximadamente 30.000 genes. También existe material genético fuera de los cromosomas, en unas pequeñas estructuras presentes en el citoplasma denominadas mitocondrias, donde ocurre la producción de energía para la células. El pequeño ADN mitocondrial, ya conocido, contiene 37 genes y se transmite exclusivamente a través del óvulo materno.

El $\mathrm{PGH}^{1}$ es un proyecto de investigación billonario cuyos objetivos son: 1) conocer la secuencia de todo el ADN humano, que contiene alrededor de 3.2 billones de bases nitrogenadas (letras), 2) identificar los $\sim 30.000$ genes y 3) conocer genes involucrados en enfermedades de causa genética y ambiental. Entre estos últimos destacan los relacionados con el cáncer, por ejemplo, de mama. En la actualidad, aunando los logros científicos obtenidos por el PGH público con aquellos alcanzados por la empresa privada (Celera Genomics), ya

1 [Sitio en Internet] Disponible en http://www.doegenomes.org/ se conoce la secuencia completa del genoma y alrededor de 22.000 genes humanos normales (junio de 2004). Ello ha impactado en múltiples áreas de la sociedad. Con todo este revuelo, existe el peligro de considerar que todas las características biológicas de un ser humano radican en sus genes (reduccionismo genético). Sin embargo, conviene señalar que los genes no actúan por separado sino que necesitan interactuar entre sí y con el ambiente para desarrollar su potencialidad. No existe una relación lineal entre un determinado gen y el fenotipo, sino que, por el contrario, existe una serie de relaciones complejas entre un determinado gen y otros genes y el ambiente para producir un fenotipo.

\section{Impacto científico del PGH en biología y medicina}

Científicamente, dos aspectos biológicos relacionados con el conocimiento del primer borrador del genoma humano han resultado muy sorprendentes. Por una parte, se estima que alrededor del 97\% del genoma no correspondería a genes, es decir, sólo un 3\% de la información genética representaría a los genes que se expresan en algún producto. En otras palabras, el 97\% del genoma no tendría alguna función conocida. Por otra parte, la comparación entre el genoma de dos personas distintas arroja un $99.9 \%$ de similaridad genética, lo que invalidaría el concepto biológico de raza. Además, la información del PGH, que revela una homología muy alta con el genoma de monos, ratones y otros mamíferos, está permitiendo abordar estudios sobre las relaciones evolutivas del hombre con otras especies.

En el ámbito de la medicina, el impacto ya producido $-\mathrm{y}$ el que se está progresivamente generando- se refiere a una nueva concepción de una medicina más preventiva, en contraste con la actual curativa. Se trata de la llamada 
"medicina genómica". El conocimiento de la constitución genética de una persona podrá ayudar a prevenir el desarrollo de enfermedades futuras, no sólo de afecciones genéticas sino que, incluso, de afecciones de causa ambiental como, por ejemplo, el conocimiento de genes de susceptibilidad para enfermedades infecciosas. En un futuro no muy lejano el actual perfil bioquímico será muy probablemente reemplazado por un "perfil genético". El conocimiento obtenido por el PGH ha permitido el desarrollo de sofisticados tests de diagnóstico genético (utilizando incluso microchips de $\mathrm{ADN}$, que en la actualidad ya pueden diagnosticar hasta 10.000 mutaciones). Estos tests pueden aplicarse a personas ya enfermas o a aquellas que todavía no han desarrollado una particular afección genética (diagnóstico presintomático). También pueden usarse para el estudio de células del feto durante su desarrollo en el vientre materno, mediante diagnóstico genético prenatal (amniocentesis, biopsia de vellosidades coriales, sangre materna, entre otros métodos). Actualmente, estos tests diagnósticos genéticos se pueden aplicar, incluso, en células embrionarias antes de la implantación de los embriones obtenidos mediante fertilización in vitro (diagnóstico genético preimplantacional). Ello no sólo permite determinar el sexo del embrión sino también pesquisar enfermedades genéticas y realizar así implantación de sólo aquellos embriones sanos ("selección embrionaria").

Por otro lado, el conocimiento del PGH está permitiendo el desarrollo de terapias génicas para intentar curar definitivamente algunas afecciones genéticas. En terapia génica se usa la tecnología del ADN recombinante para corregir un gen defectuoso y reemplazarlo, en el mejor de los casos, por el gen normal en forma permanente. Este tipo de terapia puede ser de tipo somática, que tiene validez sólo para el individuo que la recibe $-\mathrm{y}$ para la que existe gran consenso en su utilidad-, y de tipo germinal, en la que no sólo se modificaría la información genética del individuo que la recibe sino también de sus descendientes; esta técnica tiene insospechadas consecuencias, por lo que despierta grandes reservas éticas y es censurada por la inmensa mayoría de científicos. En la actualidad, ya se están llevando a cabo varios intentos clínicamente controlados de terapia génica humana.

Finalmente, el PGH contribuirá al desarrollo de nuevas drogas que permitan un tratamiento más individualizado para cada paciente de acuerdo a su constitución genética.

\section{Aspectos éticos, legales y sociales (ELSI) del PGH}

El Proyecto del Genoma Humano tiene un profundo impacto a nivel ético, legal y social (ELSI), por lo que un monto significativo de sus fondos está dedicado a analizar estas implicancias. Entre ellas conviene señalar: la identificación genética (estudios de paternidad, identificación criminalística), el acceso a la información de las características genéticas de las personas por parte de las aseguradoras de salud y empleadores, las consecuencias del conocimiento del estado de portador de una enfermedad genética que se desarrollará en el futuro y el debate de ideas eugenésicas y racistas. Un ejemplo emblemático corresponde al gen que da susceptibilidad a cáncer de mama en algunas mujeres (oncogen BRACA): si una mujer se realiza el test para este gen, ¿tienen derecho las aseguradoras de salud y los empleadores a conocer esta información antes de asegurar o emplear?

El conocimiento obtenido por el PGH ha permitido desarrollar tests de diagnóstico genético que pueden aplicarse a personas ya enfermas o a aquellas que todavía no han desarrollado una particular afección genética (diagnóstico presintomático). También pueden aplicarse para el diagnóstico antenatal y embrio- 
nario preimplantacional. En su aplicación el Consejo Genético tiene un rol esencial.

\section{Consejo Genético}

El Consejo o Asesoramiento Genético es un proceso de comunicación que se realiza en el ámbito del acto médico, en el cual se entrega información acerca de las características de las afecciones genéticas, los riesgos de ocurrencia y de recurrencia y los impactos familiares que ellas producen.

Las indicaciones habituales para entregar Consejo Genético son: enfermedad genética conocida o sospechada en un paciente o su familia; diagnóstico presintomático y antenatal de afecciones genéticas; defectos de nacimiento; retardo mental no explicado; edad materna avanzada; exposición a teratógenos; consanguinidad; y abortos espontáneos a repetición.

Sólo después de conocido el diagnóstico preciso de la afección genética, o cuando se conocen los riesgos generales en la población para presentar alguna afección genética específica, se puede proceder a ofrecer el Consejo Genético. En esas condiciones se entrega la siguiente información:

a) Magnitud del riesgo de ocurrencia y de recurrencia. Tanto el riesgo de ocurrencia como de recurrencia poseen, por definición, una naturaleza probabilística. No corresponden a certezas. Por ejemplo, el riesgo de ocurrencia para el caso del Síndrome de Down, puede estimarse de datos de ocurrencia en la población general. En este caso específico, el factor de la edad materna avanzada, aumenta el riesgo de tener un hijo con Síndrome de Down. La realización de tests genéticos durante el embarazo aumenta la probabilidad de la ocurrencia de Síndrome de Down, hasta la certeza cuando se analizan directamente las células embrionarias o fetales. Otro ejemplo lo constituyen los tests genéticos presintomáticos, tales como aquellos para pesquisa de mutaciones relacionadas con cánceres familiares. Es el caso de las mutaciones en los oncogenes BRACA 1 y 2, que confieren susceptibilidad para sufrir cáncer de mamas con un riesgo de $85 \%$.

En el caso de estimar riesgos de recurrencia, cuando ya ha habido un miembro de la familia afectado, se utiliza la información propia de la afección (por ejemplo, si la enfermedad es monogénica, autosómica dominante, tiene un riesgo a priori de recurrir en futuros hijos de $50 \%$; en cambio, si es autonómica recesiva, el riesgo a priori de recurrir es de $25 \%$ ) y la información específica aportada por cada familia en particular. Los cálculos probabilísticos habitualmente utilizan el Teorema de Bayes.

b) La carga de la enfermedad para el paciente y la familia. Se debe informar acerca de la carga clínica, financiera, social y emocional impuesta por la afección genética al paciente y/o a su familia.

c) Posibilidad de modificar la carga y/o riesgo de recurrencia. Se debe informar acerca de la posibilidad de modificar la carga y/o riesgo de recurrencia de la afección genética al paciente y/o a su familia. Muchas afecciones genéticas son tratables o prevenibles. El diagnóstico de una afección genética no necesariamente significa un camino inexorablemente mortal o invalidante.

d) Desarrollo de futuros anticipados. Se debe informar acerca de los eventuales desarrollos que estén ocurriendo en el campo de la afección genética en cuestión y que puedan incidir en eventuales tratamientos específicos (por ejemplo, terapia génica) que mejoren la calidad de vida de los afectados. La genética médica es una disciplina en continuo desarrollo. 
En el proceso del Consejo Genético la información debe ser entregada en términos simples, al alcance de las personas que la están recibiendo. Debe ser imparcial y objetiva, ya que puede involucrar conductas reproductivas que son muy personales o decisiones relacionadas con el futuro individual y familiar. Por ello, es aconsejable la cooperación de grupos de soporte (grupos religiosos, asociaciones de enfermos, por ejemplo).

Como mencionamos, el desarrollo de la medicina genómica, ha significado la implementación de numerosos tests de screening (o tamizaje) de afecciones genéticas, que permiten no sólo ayudar al diagnóstico específico, sino también pesquisar afecciones genéticas antes de que ellas se manifiesten o de que se reconozcan como tales.

Los tests de screening genéticos se clasifican en: 1) Tests postnatales, tales como el a) Screening de recién nacidos: realizado a todos los recién nacidos, pesquisando enfermedades que pueden ser detectadas de manera simple y que tienen un tratamiento específico. Por ejemplo, el screening de la fenilcetonuria e hipotiroidismo congénito que se realiza en Chile; b) Screening de individuos con riesgos de transmitir una afección genética. Por ejemplo: la pesquisa de afecciones genéticas en grupos étnicos específicos, tales como la enfermedad de Tay-Sachs en judíos Aschkenazi; c) Screening postnatal presintomático de familiares de afectados por enfermedades genéticas específicas como, por ejemplo, hijos de afectados por Corea de Huntington o Screening postnatal presintomático de individuos sin historia familar como, por ejemplo, mujeres que desean saber el estado de sus genes de susceptibilidad a cáncer de mama. 2) Tests antenatales, tales como: a) Screening fetal: pesquisa de afecciones genéticas durante el embarazo (diagnóstico prenatal), mediante: amniocentesis, biopsia de vellosidades coriales, ultrasonido; análisis de compuestos presentes en suero materno o líquido amniótico, células fetales en sangre materna, etc., y b) Screening de embriones: pesquisa de afecciones genéticas en células embrionarias (blastómeros), de embriones obtenidos mediante fertilización in vitro, antes de su implantación (diagnóstico genético preimplantacional).

\section{Aspectos bioéticos en el Consejo Genético}

El Consejo Genético, por su naturaleza de acto médico, tiene implicancias a nivel bioético muy significativas que ameritan una reflexión, primero desde una perspectiva bioética principialista y, luego, desde una perspectiva bioética personalista.

a) Perspectiva bioética principialista (se fundamenta en los clásicos principios de autonomía, beneficencia, no maleficencia y justicia)

Principio de autonomía. Los individuos poseen la capacidad de deliberar y actuar en consecuencia. El sometimiento al consejo genético debe ser libre, voluntario y sin coacción. Este principio se opone al paternalismo del médico tradicional. Requiere de una buena relación médico-paciente. El principio de autonomía se ve reflejado en el consentimiento informado. Este incluye una información sobre los procedimientos que se utilizarán y sus consecuencias. Se debe considerar la opinión del interesado en cuanto a conocer o no el diagnóstico que se está pesquisando y los eventuales impactos sicológicos de ello. En el ámbito del Consejo Genético a nivel prenatal, el médico debiera entregar toda la información técnica o, si tiene objeción de conciencia por la eventualidad que el diagnóstico prenatal conlleve a un aborto, debiera derivar al paciente a un centro especializado. 
El principio de autonomía, sin embargo, no es un principio ético absoluto que no admita excepciones. Por ejemplo, mientras mayor sea el beneficio para la sociedad y menos lesiva sea para el individuo, la exigencia de someterse a consejo genético (incluyendo screening genético) es más obligatoria. Tal es el caso del screening de recién nacidos (por ejemplo, de fenilcetonuria). Por otra parte, no parece éticamente lícito obligar a someterse a screening prenatal, ni menos aún a un eventual aborto mal llamado "terapéutico".

En el caso de los tests de screening de predisposición genética, tales como el de mutaciones en los oncogenes BRCA1 y 2, las personas bien informadas, con capacidad de tomar decisiones y aceptar sus consecuencias, pueden decidir si desean realizárselo y conocer sus resultados.

Principio de beneficencia. El estudio genético sólo debe ofrecerse cuando se estima que los beneficios del estudio sobrepasan los riesgos y que los resultados mejorarán el bienestar del individuo. La relación médicopaciente es fundamental para que este principio pueda tener lugar. Existe siempre un conflicto entre el beneficio individual y el beneficio de terceros; entre el derecho a la autonomía y la beneficencia. A modo de ejemplo, podemos mencionar el estudio genético de predisposición a cáncer. ¿Se debe revelar información a terceros sólo cuando se ha obtenido el consentimiento informado del afectado? ¿Qué sucede si el sujeto en quien se encuentra una determinada mutación solicita que los familiares no sean informados? ¿Es éticamente lícito realizar estudios genéticos en los gametos donados que se utilizarán en técnicas de fertilización asistida?

Principio de no maleficencia. El estudio genético sólo debe ofrecerse cuando no produzca daño sicológico, no altere las relaciones familiares ni ponga en peligro la situación labo- ral o de seguros médicos. Por ejemplo, el estudio genético de predisposición a cáncer en niños no es lícito realizarlo cuando no existen beneficios derivados de intervenciones a edades tempranas. Estos tests genéticos presintomáticos sólo se justifican cuando, en virtud del principio de la beneficencia, pueden ayudar a las personas. Tal es el caso de los que permiten pesquisar mutaciones específicas, como en el caso de poliposis familiar del colon (PFC). En esta afección genética, los pólipos inexorablemente degeneran en cáncer de colon. Por ello, si las mutaciones relacionadas con PFC se encuentran en niños de familias de afectados, ello significa que la aparición de pequeños pólipos conlleva a plantear colectomía radical a edades muy tempranas.

Principio de justicia. El principio de equidad o justicia establece que "todas las personas tienen derecho a igual calidad de salud". Por ello, todos los ciudadanos deben tener acceso a todos los tests genéticos necesarios sin discriminación económica, social, racial ni religiosa. Ello puesto que los tests genéticos no son más que una forma de atención médica.

Por ejemplo, un estudio genético de predisposición al cáncer. ¿Todos los individuos tienen derecho a estos tests? ¿Todos los individuos tienen derecho al mismo tratamiento?

Habitualmente, se ofrece diagnóstico prenatal a las mujeres mayores de 35 años, por riesgo aumentado de hijos con Síndrome de Down. $¿$ Tienen derecho a estos procedimientos diagnósticos las mujeres menores? ¿Dónde debe situarse la frontera del riesgo, a partir de la cual los individuos deben tener derecho al diagnóstico prenatal?

Confidencialidad. Ella surge del secreto médico, presente siempre en la ética médica desde el Juramento Hipocrático. La excepción corresponde a cuando se puede ocasionar da- 
ños a terceros o a la sociedad. A modo de ejemplo, en las enfermedades genéticas ligadas al $\mathrm{X}$, si una mujer es portadora, su pareja debiese conocer su condición de tal cuando puedan existir daños importantes para su descendencia. Cuando por estas razones debe revelarse un secreto médico, se debe procurar entregar sólo la información genética necesaria para evitar los daños posibles, evitando proveer de otra información que posea el médico y que no sea directamente atingente a la situación señalada.

\section{b) Perspectiva bioética personalista}

Esta visión se basa en la persona humana y su bien. Corresponde a la expresión de una reflexión racional sobre la persona humana en sus dimensiones física y espiritual, y que es el centro de la actividad biomédica como sujeto y objeto de la misma. Este modelo asegura una óptima relación médico paciente, en que el eje es el bien del paciente en una relación de confianza y de respeto. Incluye la información y participación del paciente en las decisiones. Cumple con las necesidades del paciente y el rol del médico, respetando la dignidad de ambos.

En la perspectiva personalista destacan los siguientes principios:

Principio de defensa de la vida física. La vida corporal y física del hombre representa un valor fundamental. A través de ella se manifiesta la persona y expresa otros valores, tales como la libertad y la sociabilidad. El respeto a la vida, así como su defensa y promoción, representan el imperativo ético más importante del hombre, en el que conviene destacar la defensa de su salud. El derecho a la vida precede al derecho a la salud. En este sentido, la aplicación de tests genéticos para detectar afecciones genéticas antenatalmente en el feto $\mathrm{o}$, incluso, en el embrión, que conlleven al aborto del feto o a la eliminación de embriones en aras de que los afectados tendrán una mala calidad de vida, se contrapone con el principio básico de la defensa de la vida física. La detección de afecciones genéticas en los fetos mediante tests genéticos prenatales ha sustentado la eliminación de miles de seres humanos a través de un tipo de aborto mal llamado "terapéutico", pues se trata de un aborto con claras características eugenésicas.

El caso del diagnóstico genético de embriones obtenidos por fertilización in vitro, antes de su implantación, plantea una situación de consejo genético complicada, pues puede llevar a selección embrionaria. Es decir, los padres pueden elegir a los embriones que deseen y desechar aquellos que no. ¿Los padres tienen derecho a decidir sobre la vida de sus hijos?

Principio de libertad y responsabilidad. La libertad debe ejercerse responsablemente ante la vida propia y la ajena. La vida y la salud se han encomendado a la responsabilidad del paciente, ayudado por su médico. En relación con este principio, el consentimiento informado es importante y muy especialmente en lo que se refiere al Consejo Genético. El médico debe informar a su paciente de la condición genética que posee y del curso de los acontecimientos inherentes a aquella condición. Luego de informar lo referente a la enfermedad, si el médico considera éticamente inaceptables los deseos del paciente, puede deslindar responsabilidad invitando a reflexionar al paciente y, eventualmente, referirlo a otro médico. Ni la conciencia del paciente debe violentarse por el médico ni la del médico por el paciente. Ello es particularmente relevante en los casos de diagnóstico genético prenatal y preimplantacional, que puede conducir a la eliminación de seres humanos en estado fetal o embrionario.

Un caso dramático se ha vivido recientemente: abusando del principio de libertad, padres de niños deformes por afecciones genéticas irreversibles, han recurrido a eutanasia neonatal. 
Principio de totalidad. La corporeidad humana es un todo unitario. Existe una totalidad física, espiritual y moral de la persona. Este principio de la totalidad rige la licitud y obligatoriedad de la terapia médica y quirúrgica, de ahí que se conoce también como principio terapéutico. Al realizar Consejo Genético para una afección como la poliposis familiar del colon, por ejemplo, se debe comprender que la enfermedad, si bien afecta al intestino grueso, compromete a la totalidad del paciente en su dimensión física y espiritual. En aquellos hijos de afectados con esta condición, y que a temprana edad infantil ya presentan pólipos, ateniéndose al principio terapéutico se les debe ofrecer intervención quirúrgica preventiva (colectomía-total).

Principio de sociabilidad y subsidiaridad. La vida y la salud corresponden a un bien social. Toda persona debe comprometerse a considerar su propia vida y salud y la de los demás como un bien personal y social. Este principio obliga a la comunidad a promover la vida $\mathrm{y}$ salud de todos y cada uno.

La subsidiaridad comienza por el respeto a la autonomía del paciente, es decir, atender a sus necesidades sin sustituirle su capacidad de decidir y actuar. Ello es particularmente relevante en el Consejo Genético, en casos de decisiones reproductivas derivadas de la entrega de información sobre las afecciones genéticas y los riesgos de recurrencia, y también en casos de diagnóstico genético presintomático, antenatal y preimplantacional.

El principio de sociabilidad-subsidiaridad obliga a la comunidad a ayudar donde la necesidad sea mayor. Ello obliga, por ejemplo, a establecer políticas de salud pública para cubrir a toda la población, como ocurre con los tests de screening neonatal de afecciones genéticas. En Chile esto es una realidad para dos afecciones genéticas: fenilcetonuria e hipotiroidismo congénito, cuyo screening a los recién nacidos es una realidad en los hospitales públicos y clínicas privadas.

Por las características anteriormente mencionadas, considero que la perspectiva personalista corresponde al modelo más apropiado para enfrentar el Consejo Genético, dado que se trata de un acto médico que requiere una relación de confianza y respeto entre el médico y su paciente y que involucra la participación activa por parte de este último en las decisiones.

\section{Consideraciones finales}

En la medicina de la era genómica, el Consejo Genético plantea interrogantes bioéticas de gran trascendencia que obligan a una reflexión desde múltiples puntos de vista, tales como el antropológico, médico y social. Esta reflexión debe realizarse a la brevedad para poder enfrentar el gran desarrollo de la genética médica en la medicina genómica que ya se vislumbra. La perspectiva bioética personalista representa un buen camino para enfrentar este desafío. Uno de los marcos referenciales para esta discusión lo constituye la Declaración Universal sobre el Genoma Humano y los Derechos Humanos (UNESCO, París, 11 Noviembre de 1997): “Las investigaciones sobre el genoma humano y sus aplicaciones abren inmensas perspectivas de mejoramiento de la salud de los individuos y de toda la humanidad, pero destacando que deben, al mismo tiempo, respetar plenamente la dignidad, la libertad y los derechos de la persona humana, así como la prohibición de toda forma de discriminación fundada en las características genéticas". 
Aspectos Bioéticos del Consejo Genético en la Era del Proyecto del Genoma Humano - M. Santos

\section{Bibliografía}

Beauchamp TL, Childress JF. Principles of biomedical ethics. Oxford: Ed. Oxford University Press; 1989.

Bentley D. Genomes for Medicine. Nature 2004; 429: 440-50.

Braunwald E, Fauci AS, Kasper DL, et al., eds. Harrison's Principles of Internal Medicine. 14th Edition. Part III: Genetics and Disease. McGraw-Hill Professional; 1998: 365-409.

Burke W. Genetic testing. The New England Journal of Medicine 2002; 347(23): 1867-75.

Cruz-Coke R. Declaración Universal sobre el Genoma Humano y los Derechos Humanos (UNESCO, París, 11 Noviembre 1997) Revista Médica de Chile 1997; 125: 1485-89.

Chomalí F, Madrid R, Repetto G, Rigotti A, Rodríguez E, Santos MJ, Vicuña R. Proyecto Genoma Humano. Presente y perspectiva futuras. Consideraciones biológicas, médicas, filosóficas, jurídicas y éticas. Humanitas 1999; 15: 1-32.

Elias N, Annas T. Generic consent for genetic screening. The New England Journal of Medicine 1994; 330 : 1611-13.

Fleming DA. Ethical considerations of genetic testing. The Journal of Clinical Ethics 2002; 13(4). 316-23.

Gafo J. Problemas éticos de la manipulación genética. Madrid: Ediciones Paulinas; 1992.

Geller G, et al. Genetic testing for susceptibility to adult-onset cancer. The process and Content of informed consent. JAMA 1997; 277: 1467-74.

Genome panel defends researchers' -and families' -interests. (editorial) Nature 1998; 391: 826.

Gracia D. Fundamentación y enseñanza de la bioética. Bogotá: El Búho; 1998.

Gracia D. Bioética clínica. En: Gracia D. Ética y Vida (2). Bogotá: El Búho; 1998: 69-82.

Grody WW. Molecular genetic risk screening. Annual Review of Medicine 2003; 54: 473-90.

McAbee GN, et al. Physician's duty to warn third parties about the risk of genetic diseases. Pediatrics 1998; 102: 140-42.

Pellegrino ED. Thomasma DC. For the Patient's Good. The Restoration of Beneficence in Health Care. New York: Oxford University Press; 1988.

Phadke SR. Genetic counseling. Indian. The Journal of Pediatrics 2004; 71(2): 151-56.

Santos MJ. El Proyecto Genoma Humano. Revista Universitaria 2001; 71: 10-13.

Santos MJ. Las cuatro letras de la vida. 50 años después. Revista Universitaria 2003; 80: 19-21.

Screggia E. Manual de Bioética. México: Diana; 1994.

Trent RJ, Williamson R, Sutherland GR. The "new genetics" and clinical practice. The Medical Journal of Australia 2003; 178(8): 406-09. 